\title{
Miscelánea
}

\section{Code of Ethics}

1111111

$|1| 1|1| 1|1| 1 \mid$

\section{La ética de la bioética}

The Ethics of Bioethics

B) Autor

\author{
Javier Sádaba Garay \\ Universidad Autónoma de Madrid \\ E-mail: javiersadaba2811@gmail.com
}


Resumen

Abstract

Key words
El artículo expone, en síntesis, el estado de la cuestión del campo de la bioética. Trata del vínculo indisoluble con la ética y presenta una propuesta epistemológica para el ámbito de conocimiento de la bioética.

The article exposes, in synthesis, the state of the matter of the field of Bioethics. Is the indissoluble link to Ethics and presents an epistemological proposal for the scope of knowledge of bioethics?

Bioética; ética; epistemología de la bioética.

Bioethic; Ethics; Epistemology of Bioethics.

Recibido: 30/09/2019. Aceptado: 21/01/2020 
El título, a primera vista, parece redundante. Se elimina la redundancia si se aclara que puede haber más de una ética y que, en consecuencia, es necesario especificar de qué ética se está hablando. Para ello conviene hacer unas observaciones previas que nos posibiliten avanzar hasta el final. Estamos ante una mínima parte de la acción humana. Y, por tanto, dentro de una teoría de la acción. Lo que sucede es que después del libro La acción humana, del célebre economista Von Mises, dicha acción suele ser referida a la economía. A nosotros nos importa, sin embargo, tomarla en toda la extensión. Y su

Se distribuye con profusión la
frase de S. Toulmin según la
cual la bioética ha salvado a la
ética al sacarla de su letargo.
Aunque exagerada tiene la
virtud de mostrar que la ética ha
de estar girando continuamente
la cabeza para saber qué es lo
que permanece y cambia en
este mundo
extensión va desde un ser que se supone que actúa libre y responsablemente hasta una meta a la que llega a través de los medios que considera más apropiados. Ocurre lo mismo que en el terreno teórico puesto que partimos de una intención para lograr un fin y utilizamos los medios o instrumentos que nos parecen más oportunos. Los humanos no somos, una pena, como el Dios de la teología medieval que en un acto entendía todo y hacía todo. Las acciones que llamamos buenas o malas componen esa parte teórica y práctica activa y que incide en el mundo mejorándolo o empeorándolo. Una vez situado el rango amplio en donde habita la ética se impone hacer una serie de distinciones.

Digamos antes de nada que la bioética, de cuya ética vamos a hablar, es lo que se ha dado en llamar una ética aplicada. La expresión no quiere decir que la ética ha cambiado o que nos encontramos ante una nueva ética, sino que se ha desarrollado de manera extraordinaria un campo de la realidad que exige una atenta y concentrada mirada ética. Para lo cual, es obvio, que se ha de tener el mayor conocimiento del campo en cuestión. Si se desconoce qué es y cómo es la epigenética, mejor dedicarse a otras labores. Ocurre algo parecido con la ética aplicada a los animales dado el conocimiento que hemos adquirido de ellos y los problemas nuevos que plantean. Otra vez hemos de decir que hay que volverse a los animales y, distinguir, por ejemplo, entre un caracol, un cerdo, un bonobo o un neandertal. Y si se desconocen tales diferencias mejor dedicarse a otras labores o entretenimientos. Algunos piensan que está de sobra la ética aplicada o que es un rizo de rizo sin más. Se puede pensar lo contrario, que la ética aplicada deja de enredarse en sí misma y se estira como las jirafas hacia los muy distintos hechos del mundo. Se atribuye y se distribuye con profusión la frase de S. Toulmin según la cual la bioética ha salvado a la ética al sacarla de su letargo. Aunque exagerada tiene la virtud de mostrar que la ética ha de estar girando continuamente la cabeza para saber qué es lo que permanece y cambia en este mundo.

La bioética, palabra compuesta de vida y de ética, ha surgido recientemente con fuerza en los últimos decenios y la causa hay que encontrarla en los enormes cambios que van desde el conocimiento celular hasta la inteligencia artificial como en su momento veremos. No deja de ser curioso que numerosos clérigos se interesaron pronto en la materia. Y es que la Iglesia ha querido ser siempre la guardiana de la vida y la muerte. No podía, por eso, desinteresarse de lo que, si va a otras manos, las suyas quedan vacías. 
Sigamos con las observaciones previas antes de pasar a lo más nuclear de la ética y su reflejo en la bioética. Suelen usarse indistintamente las palabras ética y moral. Convendría, sin embargo, aclarar su significado y de esta manera evitar confusiones. Una de las diferencias estriba en su etimología puesto que "ética" proviene del griego y "moral" del latín. Ética se puede traducir por hábito, costumbre y hasta carácter, mientras que la moral hace referencias a las costumbres. Otra diferencia proviene del uso, un tanto arbitrario, que los filósofos han hecho de ambos términos con lo que la confusión aumenta. Y otra la utilización como sinónimas o como si una, la ética en general, se limitara a enfatizar a la moral. Tal vez lo correcto consista en llamar ética, y eliminar el plural "éticas", a unos principios básicos que todo el mundo debería compartir si quiere comprenderse a sí mismo como humano. Por ejemplo, no matar si no es en legítima defensa, no torturar, no humillar a nadie y considerar a todo el mundo con los mismos derechos. Quien no se sometiera a tales principios sería alguien radicalmente inmoral. No amoral puesto que la amoralidad es un imposible ya que el más perverso ha de someterse, si vive en sociedad, a alguna norma mínima.

Bajo el gran paraguas de la ética se encuentra la moral. Porque la moral consiste en un código de conducta que rige en una comunidad y no en otra. $Y$ en ocasiones pueden coexistir códigos de conducta en la misma sociedad
Por cierto, hay quien dice que la ética y los derechos humanos universales son lo mismo. Y no es así, porque dichos derechos, que no son, de facto, universales -ya que hay países, como los musulmanes, que no los aceptan- $y$, por otro lado, no se sabe cuántos son, puesto que parecen un saco sin fondo, y los más relevantes se basan en la ética y no llueven ni del cielo ni de la Sra. Roosevelt, que fue quien más los amparó. Bajo el gran paraguas de la ética se encuentra la moral. Porque la moral consiste en un código de conducta que rige en una comunidad y no en otra. $Y$ en ocasiones pueden coexistir códigos de conducta en la misma sociedad. Piénsese, por ejemplo, en la eutanasia. En nuestro país la eutanasia está penada en el Código Penal, pero es probable que sean mucho más los que estén a favor de una eutanasia regulada. Eso solo se resuelve argumentando y votando, y sin interferencias religiosas. Es verdad que a veces da la impresión de que entre la ética y la moral hay una línea de separación muy fina, pero eso no excluye que sea radicalmente diferente el ejercicio de la eutanasia, que es un acto de amor, que el asesinato, que lo es de odio. No habría que olvidar tampoco que algo no vale simplemente por ser costumbre. $Y$ es que hay costumbres indiferentes, como saltar a la comba, bellas, como jugar al fútbol, y que dejan de ser morales por chocar con la ética, como es la ablación del clítoris.

Esto supuesto, hagamos un gráfico de cómo funciona la acción moral a la que en su momento nos hemos referido. Por un lado, está el sujeto de las acciones. Como ha de ser responsable de tales acciones hemos de suponer que es libre. Se trata de una suposición puesto que ofrecer un argumento decisivo sobre nuestra libertad no es posible. Desde la antigua Grecia hasta nuestros días se le han puesto mil objeciones a la libertad y se ha afirmado que estamos determinados como lo está la tierra a dar vueltas alrededor del sol. No entraré en las razones en pro o en contra de la libertad. Me parece suficiente para sostener que, al menos en algunas de nuestras acciones, somos libres de recurrir a la idea de "forma de vida" de Wittgenstein. Nuestro lenguaje, y nuestra vida, en suma, adquieren significado en un contexto. $Y$ es en ese contexto donde tiene 
significado hablar de libertad. Si esta se eliminara podríamos pensar que somos superhumanos o simios, pero no humanos. No sabríamos qué significa ser humano. Y de ahí no podemos pasar.

Quien se dedique a la bioética ha de dar un paso más y deberá hacerse una idea lo más cabal posible de lo que entendemos por libertad, lo que implica que estudie, por ejemplo, lo que nos están enseñando las neurociencias. En caso contrario puede ser muy intuitivo o acumular mucha experiencia, pero andará a ciegas.

El sujeto que actúa libremente lo hace en función de alcanzar un fin o meta y para ello no tiene más remedio que dar pasos en dirección al objetivo que desee lograr. La acción del sujeto no tiene más remedio que sortear obstáculos, aprovechar ocasiones, usar, en suma, los medios o instrumentos que le aproximen a lo que desea obtener. En algún sentido, pueden llamarse fines o metas parciales. Si el sujeto es cuerdo desechará los que no le sirvan y utilizará los mejores, aunque como en todo, no hay blanco y negro, sino pequeñas metas intermedias que le bastan para con-

En muchas ocasiones los

medios son un peligro. Más aun, pueden ser la destrucción de un sano proyecto tinuar avanzando. En este terreno de la acción humana se produce un fenómeno que modifica lo que sería una línea que posee un comienzo y un fin limpios. Y, desgraciadamente, no es así. En muchas ocasiones los medios son un peligro. Más aun, pueden ser la destrucción de un sano proyecto. Quedémonos en el terreno político donde los ejemplos abundan de tal manera que trastocan la más admirable de las tareas humanas. Imaginémonos un movimiento político que lucha con toda sensatez contra una tiranía a la que habría que derrocar. Dicho movimiento acumula todo aquello que le venga bien para eliminar un mal. Pero cuando descubre el poder que ha adquirido, se olvida pronto del deseo principal y convierte el medio en un fin; un fin que le interesa a quien hablaba en nombre del oprimido y ahora juega él a opresor. El Poder le ha cegado. El Poder, diosecillo que se cuela por todas las esquinas, hace que se reproduzca lo peor de la vida humana: la autosatisfacción pisoteando a los demás. En las relaciones bioéticas, como podría ser una intervención quirúrgica, es fundamental ponderar todos aquellos elementos que necesite la salud del paciente. 0 el del reconocimiento facial, que es tema de intenso debate en nuestros días. De la misma forma que podría servirnos para detectar un peligroso terrorista puede parecer un ataque a la privacidad dado que el rostro es parte esencial de la persona siendo usada sin su permiso para objetivos bien alejados de la persona en cuestión. Llegamos a la última parte, al fin de la acción. Una vez que se han puesto en práctica los medios -los muchos entrenamientos de Messi, por ejemplo, para ser un gran jugador de futbol. Estará en su mano, en su pie, ser el mejor jugador del mundo. Si era ese su deseo final habrá conseguido su máximo deseo-. Aristóteles pensaba que es un solo deseo el que nos hacía feliz puesto que la consecución de lo que más nos interesa es la felicidad. Y cuanto más alto y grandioso sea el fin, mayor sería la felicidad. Tal idea de felicidad centrada en un solo aspecto no es de recibo. En general buscamos varios fines últimos y el conjunto de tales fines es lo que llamamos felicidad. Es a ese conjunto al que llamamos vida buena, bienestar o la ya gastada palabra de felicidad. La bioética tendrá que colaborar a la consumación, siempre limitada por humana, del buen vivir o vida buena. 
Es el momento de pasar directamente a la bioética para, al final, colocar sobre ella la ética. De bioética se han dado decenas de definiciones lo que, si seguimos a Popper, habría que prescindir de todas ellas. Podemos, eso sí, quedarnos con un núcleo al que ya nos referimos al principio y según el cual se trata de una reflexión sobre la vida en función de los avances espectaculares de los últimos tiempos. Lo que ha sucedido, por desgracia, es que en muy poco tiempo han surgido bioéticos como hongos. Basta ponerse el pin de bioético y se está listo para ser profesor de la materia, lo que es un verdadero despropósito.

Lo que haré ahora es ofrecer un cuadro que recoja lo debería incluir la disciplina sin rellenar todo aquello que le daría un cuerpo entero. Para ello la dividiré en cuatro partes que la encuadren. Las de las esquinas son las más decisivas y las dos que aparecen en medio son auxiliares o si se quiere complementan los extremos citados. Tales extremos, que, en lo que hace al contenido son centrales, son las ciencias empíricas, y sobre todo la biología y, en el otro lado, las humanidades con la salud como su cabeza. Pero comencemos con las que se sitúan en medio

\section{El bioético deberá decidirse}

entre actuar bajo la ley o bajo la

moral; una moral siempre dentro

de la ética. Es ese su problema

y para ello no tiene más remedio

que conocer la legislación en

vigor y la ética. Algo que habría

que evitar en este terreno es el

legalismo y que son el derecho y la medicina. Leyes, normas, convenios y pactos tanto nacionales como internacionales nos inundan. Vivimos en un mar de leyes. $Y$ algunas afectan de frente a la bioética. Por ejemplo, la interrupción voluntaria del embarazo es legal, bajo determinadas condiciones, en España. Otros, sin embargo, opinan, y generalmente procedentes del campo de la religión, que aunque sea legal no es legítima. 0 lo que es lo mismo, que es inmoral y debería prohibirse. Permítaseme opinar que para mí es legal, legítima y tiene, además, legitimación, que es la aprobación mayoritaria del pueblo. La gemelación, o división en dos de una célula embrionaria en una placa de Petri, no es legal en España mientras que otros la consideramos legítima o que no atenta contra la moral. El bioético deberá decidirse entre actuar bajo la ley o bajo la moral; una moral siempre dentro de la ética. Es ese su problema y para ello no tiene más remedio que conocer la legislación en vigor y la ética. Algo que habría que evitar en este terreno es el legalismo. Es este un país que rezuma leyes lo que indica que si hay tantas es porque no se respetan las pocas realmente respetables. De esta manera el derecho absorbe la bioética, la parcializa. Pasemos a la medicina. Es natural que la medicina, y lo que hoy recibe el nombre de biomedicina, ocupen un lugar especial dentro de la bioética. $Y$ es que la relación entre el equipo médico profesional y los pacientes configuran una parte esencial de la vida. Médico y enfermo, con todo lo que ello supone de investigación y relación con el mundo en general han sido, en buena parte, los detonantes del nacimiento de esta disciplina. Es esa la razón de que la profesión médica en general y los legos en la materia confundan la biomedicina con el aborto, la eutanasia, el mantenimiento de la salud, las enfermedades, los paliativos, la gestión hospitalaria y un largo etcétera. Por supuesto que el que cura y cuida ha de estar al tanto de los nuevos fármacos o nuevas tecnologías relacionadas con todo tipo de patologías. Y, al mismo tiempo, ha de mirar, como en un espejo la ética que sobre todo manda, la voluntad del enfermo o familiares y tutores. Una atinada formación en el trato con 
quien se encuentra en un estado en el que el cuerpo se deteriora es fundamental. Pero de ahí no sigue la reducción que se ha hecho y se sigue haciendo de la bioética a unos principios que carecen de autoridad y que son arbitrarios en su jerarquización.

Es, por eso, falso que la bioética se ciña a los así llamados "principios de la bioética". Es falso porque se están refiriendo a la parte clínica de la bioética y esta, como hemos visto y veremos, es mucho más. Un par de libros de gran éxito de ventas han sido los que han logrado esa intolerable reducción. Como es intolerable que se enseñen, como si fuera todo el hacer biomédico. A algunos les está siendo muy rentable darle vueltas y vueltas a los cuatro principios en cuestión. Más provechoso sería guiarse por unos bienes primarios y poder consultar a simples pero claros proto-

La biomejora posee dos caras.

\section{Una es la positiva y busca}

aplicar la tecnología más

refinada para curarnos. Otra

sería aquella que intentaría

convertirnos en semidioses colos o comités asistenciales de bioética. Tengo la impresión de que, por el momento y ante la avalancha de intereses, es como predicar en el desierto.

Las dos columnas que encierran la bioética son la de las ciencias empíricas, con la ayuda de las formales, y las humanidades, muy copiosas en su contenido. La bioética, como dijimos, nació, en cuanto disciplina, en los años setenta. Pero venía preparándose de lejos. Piénsese en el primer trasplante de corazón por parte de Bernard en los años sesenta y sobre todo en el descubrimiento de la doble hélice de nuestro genoma en 1953

por parte de Crick y Watson. Después una carrera veloz, acelerada. Actualmente, y dando saltos de gigante, el bioético ha de tener un conocimiento más que elemental, de genética, de epigenética, de neurociencias y de ciencias de la computación, y muy especialmente de la inteligencia artificial, más todo el transhumanismo que se le asocia. Tarea ingente sin duda, pero no tiene más remedio que estar al tanto al menos con aquellos datos que exijan poner en marcha la moral con sus principios. No tener idea alguna de todo ello es, digámoslo de nuevo, un fraude y un pariente de un fraude. En el otro extremo se sitúa la salud de la que, no menos, se han dado y se dan decenas de definiciones. De lo que se trata es de conocer el cuerpo humano con sus carencias desde el punto de vista individual, de tratar al enfermo como otro que es igual que tú, y de espíritu de reciclaje para no perder de vista qué es aquello que puede mejorar nuestros cuerpos. La biomejora posee dos caras. Una es la positiva y busca aplicar la tecnología más refinada para curarnos. Otra sería aquella que intentaría convertirnos en semidioses. Esta abunda en detractores. Habría que ser menos pacatos y no mirar a lo mejor como si, por encanto, se convirtiera en superioridad de unos sobre otros. Ahí es donde entra lo político, evitando la discriminación entre humanos. Y, al mismo tiempo, a los políticos hay que exigirles que coloquen en el primer lugar, y muy destacada, la partida que se destine a la atención sanitaria. El resto palidece ante lo que pide la salud, el bienestar, la vida buena.

Es obvio que unos se especializarán más en uno de los cuatro apartados a los que nos hemos referido. Pero se exige un esfuerzo para no ser analfabeto en ninguno de ellos. $Y$ ahora, si queremos sintetizar cuál es la ética de la bioética, habría que decir lo siguiente: antes de nada, un curso de ética y su compañera la moral. Después, ser experto en uno de los cuatro apartados que hemos hecho, dando primacía a la ciencia biológica y a la 
salud. Finalmente, no parcializarla hasta deformarla y convertirla en un juego de redes, reuniones, repeticiones y más y más burocracia. Luchar contra la injusta división entre ricos y pobres y no olvidar nunca que el fin es la vida buena, que evite, en lo posible, el sufrimiento. 